\title{
Social inequalities in secondhand smoke exposure in children in Spain
}

\author{
Maria J. López ${ }^{1,2,3,4}$, Teresa Arechavala ${ }^{1,3}, X^{2}$ avier Continente ${ }^{1,2,4}$, Anna Schiaffino ${ }^{5}$, Mónica Pérez-Ríos ${ }^{2,6,7}$, Esteve Fernández $z^{8-10}$
}

\begin{abstract}
INTRODUCTION Children are particularly vulnerable to the health effects of secondhand smoke (SHS). The objectives of this study are to describe SHS exposure of children younger than 12 years in Spain and to identify potential social inequalities associated with SHS exposure. METHODS A cross-sectional study was conducted in a representative sample of the population younger than 12 years in Spain. A computerassisted telephone interview was conducted with parents or legal guardians in 2016, to assess the children's SHS exposure at home, in the car, at school and at the nursery gates, in public transport, and during leisure time. The socio-demographic variables included were the child's age and sex, the highest educational attainment at home, and occupational social class. Prevalence and 95\% confidence intervals were calculated for SHS exposure in each setting and for overall exposure.

RESULTS In all, $71.8 \%$ of the children were exposed to SHS: $25.8 \%$ were exposed at home, $4.6 \%$ in the car, $8.2 \%$ in public transport, $31.9 \%$ at outdoor nursery or school gates, and $48 \%$ during leisure time. The higher the educational attainment at home, the lower the exposure (38.8\% for primary school or lower, $28.7 \%$ for secondary school and $20.8 \%$ university level). The more deprived the social class, the higher the exposure $(21.7 \%$ class I-II, $23.4 \%$ class III-IV and $31.1 \%$ class V-VII). SHS exposure in cars and overall exposure also decreased with higher educational achievement.

CONCLUSIONS In Spain, a large proportion of children are still exposed to SHS. Furthermore, there are clear social inequalities. To reduce SHS exposure, there is an urgent need for evidence-based interventions with an equity perspective.
\end{abstract}

ABBREVIATIONS SHS: secondhand smoke, SES: socioeconomic status, Cl: Confidence Interval NHS: National Health Survey, aPR: adjusted Prevalence Ratio

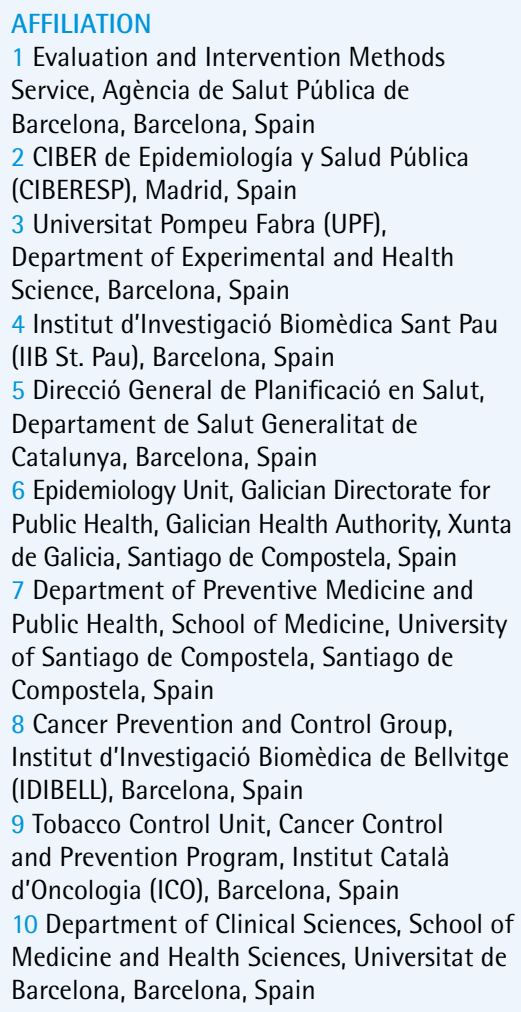

9 Tobacco Control Unit, Cancer Control and Prevention Program, Institut Català d'Oncologia (ICO), Barcelona, Spain

10 Department of Clinical Sciences, School of Medicine and Health Sciences, Universitat de Barcelona, Barcelona, Spain

\section{CORRESPONDENCE TO}

Maria J López. Evaluation and Intervention Methods Service, Agència de Salut Pública de Barcelona, Lesseps 1, 08023, Barcelona, Spain. E-mail: mjlopez@aspb.cat

\section{KEYWORDS}

tobacco smoke pollution, secondhand smoke, children, inequalities

Received: 28 December 2017
Revised: 15 February 2018
Accepted: 24 February 2018

\section{INTRODUCTION}

Children are particularly vulnerable to the health effects of secondhand smoke (SHS), mainly due to their developing respiratory and immune systems and faster respiratory rate. In addition, infants can spend long periods in the arms or on the laps of their parents or caregivers, making them very close to the source of smoke ${ }^{1}$. According to some studies, children whose parents are smokers with low socioeconomic status (SES) might be at increased risk of SHS exposure in 
the home ${ }^{2}$.

In 2006, a tobacco control law was implemented in Spain, banning smoking in workplaces and public places, except for hospitality venues ${ }^{3}$. This law was modified 5 years later, banning smoking in all hospitality venues. The 2011 law recognized that children were 'a vulnerable group to be protected' and established specific measures to protect them, such as the ban on smoking in outdoor children's playgrounds ${ }^{4}$. However, the law did not cover some of the settings where children might spend most of their time, such as homes and cars.

Data on the prevalence of exposure among children in Spain are very scarce. So far, only the Spanish National Health survey (NHS) has reported some national data, but only in home and indoor public places. In 2011-2012, according to the Spanish NHS, $11.5 \%$ of children younger than 15 years were exposed to SHS at home and less than $1 \%$ in indoor public places ${ }^{5}$.

Information on SHS exposure of children at the national level, in a wider range of settings, so far has not been available. Therefore, the objectives of this study are to describe SHS exposure of children younger than 12 years in Spain and to identify potential social inequalities associated with SHS exposure.

\section{METHODS}

This cross-sectional study was performed in a representative sample of the population younger than 12 years in Spain. The sample consisted of 2411 individuals and was proportional by geographical region, size of municipality of residence, sex, and age groups (0-1, 2-3, 4-5, 6-7, 8-9, 10-11 years).

A computer-assisted telephone interview was conducted with parents or legal guardians in 2016 . Participants were contacted using randomly selected mobile phones $(n=773)$ and landlines $(n=1638)$. The selection of households was made proportionally according to previously established quotas.

Participants were asked about children's SHS exposure at home, in the car, at school and nursery gates, on public transport, and during leisure time. To assess SHS exposure at home, we asked if any household member normally smoked inside the house and/or outdoors such as the terrace or balcony. SHS exposure in the car was determined from the time the child had spent in a private car while someone smoked in the last week (categorized as $0 \mathrm{~min} /$ day, $30 \mathrm{~min} /$ day, $31-60 \mathrm{~min} /$ day, $>60 \mathrm{~min} /$ day, don't know). The child was considered to be exposed in the car if someone had smoked $\geqslant 1 \mathrm{~min} /$ day in the child's presence. SHS exposure on public transport was assessed by asking if the child had used a means of transport in which someone had smoked (yes/no) and if someone had done so at the transport stop (yes/no). Exposure at the school or nursery was determined by the following question: 'During the last week, has anyone smoked at the entrance/ exit door in their presence? (Yes/No; Does not go to school or nursery; Don't know). In the case of leisure time outside the home, we asked about SHS exposure in different settings (bars, cafeterias, restaurants or terraces, leisure centers, parks, family or friends' houses, and other places) during the last week (Yes/ No; Don't know). All the variables were dichotomized and overall exposure was defined as SHS exposure in at least one setting (Yes/No).

The socio-demographic variables considered were the child's age and sex, and the highest educational attainment at home. We also included occupational social class, based on the National Classification of Occupations (NCO-2011) of the main earner at home ${ }^{6}$.

We calculated the prevalence and $95 \%$ confidence intervals (CI) for SHS exposure. We also performed analyses stratified by children's age, sex, and also the educational attainment and social class of the main earner at home. The p-value for trend was also assessed. Finally, we fitted robust Poisson models for each setting and adjusted them by children's sex, age, and studies of the main earner at home. All analyses were performed with Stata 13.1.

This study was approved by the 'Parc de Salut Mar Clinical Research Ethics Committee' and is registered under code 2015/6501/I.

\section{RESULTS}

Half of the sample (51\%) were boys. The highest educational attainment at home was university education in $50 \%$ of the families, and secondary school education in $40 \%$. A total of $70.9 \%$ of the households had no smokers. Most respondents were 31-50 years old, and $61.8 \%$ of the survey respondents were women. 
As shown in Tables $1 \mathrm{~A}$ and $1 \mathrm{~B}, 71.8 \%$ of the nursery or school gates and $48 \%$ during leisure time. children were exposed to SHS. A total of $25.8 \%$ were The highest prevalence of exposure during leisure exposed at home, $4.6 \%$ in the car, $8.2 \%$ on public time was observed in outdoor terraces in bars, transport (including stations), $31.9 \%$ in outdoor cafeterias and restaurants $(26.0 \%$, data not shown

Table 1A. Prevalence and prevalence ratio of SHS exposure in different private settings by children's sex and age, social class and education of the main earner at home, Spain, 2016

\begin{tabular}{|c|c|c|c|c|c|c|c|c|c|c|c|c|}
\hline & \multicolumn{6}{|c|}{ Home } & \multicolumn{6}{|c|}{ Car } \\
\hline & n & $\%$ & $95^{\circ} \% \mathrm{CI}$ & $p^{b}$ & $\mathrm{aPR}$ & $95^{\circ} \circ \mathrm{CI}$ & n & $\%$ & $95 \% \mathrm{CI}$ & $p^{b}$ & aPR & $95^{\circ} \% \mathrm{CI}$ \\
\hline TOTAL & 622 & 25.8 & $24.1-27.6$ & & & & 109 & 4.6 & $3.8-5.5$ & & & \\
\hline \multicolumn{13}{|l|}{ Sex } \\
\hline Boys & 319 & 25.9 & $23.6-28.5$ & & 1 & & 58 & 4.8 & $3.7-6.1$ & & 1 & \\
\hline Girls & 303 & 25.7 & $23.2-28.2$ & & 0.91 & $0.63-1.31$ & 51 & 4.4 & $3.3-5.7$ & & 0.98 & $0.86-1.12$ \\
\hline Age (years) & & & & & & & & & & 0.01 & & \\
\hline $0-3$ & 188 & 25.5 & $22.5-28.8$ & & 1 & & 27 & 3.7 & $2.5-5.3$ & & 1 & \\
\hline $4-7$ & 198 & 24.6 & $21.8-27.7$ & & 0.93 & $0.56-1.56$ & 28 & 3.5 & $2.5-5.1$ & & 0.94 & $0.79-1.12$ \\
\hline $8-11$ & 236 & 27.1 & $24.3-30.1$ & & 1.62 & $1.04-2.54$ & 54 & 6.3 & $4.8-8.1$ & & 1.02 & $0.86-1.20$ \\
\hline $\begin{array}{l}\text { Education of } \\
\text { home main earner }\end{array}$ & & & & $<0.001$ & & & & & & 0.002 & & \\
\hline Primary & 135 & 37.8 & $32.9-43.0$ & & 2.07 & $1.24-3.44$ & 24 & 6.8 & 4.6-9.9 & & 1.89 & $1.58-2.26$ \\
\hline Secondary & 274 & 27.8 & $25.1-30.7$ & & 1.60 & $1.04-2.44$ & 51 & 5.3 & $4.1-6.8$ & & 1.39 & $1.19-1.63$ \\
\hline University & 212 & 20.0 & $17.7-22.5$ & & 1 & & 34 & 3.2 & $2.3-4.5$ & & 1 & \\
\hline $\begin{array}{l}\text { Social class of the } \\
\text { main earner }\end{array}$ & & & & $<0.001$ & & & & & & 0.09 & & \\
\hline I-II & 190 & 21.7 & $19.1-24.6$ & & & & 31 & 3.6 & $2.5-5.0$ & & & \\
\hline III-IV & 119 & 23.4 & $19.9-27.3$ & & & & 24 & 4.8 & $3.2-7.0$ & & & \\
\hline V-VII & 284 & 31.1 & $28.2-34.2$ & & & & 47 & 5.2 & $4.0-6.9$ & & & \\
\hline
\end{tabular}

aPR: adjusted Prevalence Ratio, $\mathrm{Cl}$ : Confidence Interval

a Social class according to the National Classification of Occupations (NCO-2011) proposed by the Spanish Society of Epidemiology6 (I-II: Directors, managers and university professionals; III-IV: Intermediate activities and own account workers; V-VII: Manual workers), b Mantel-Haenzel Test for linear trend

Table 1B. Prevalence and prevalence ratio of SHS exposure in different public settings by children's sex and age, social class and education of the main earner at home, Spain, 2016

\begin{tabular}{|c|c|c|c|c|c|c|c|c|c|c|c|c|}
\hline & \multicolumn{6}{|c|}{ Public transport (including stations) } & \multicolumn{6}{|c|}{ School \& nursery gates } \\
\hline & n & $\%$ & $95^{\circ} \% \mathrm{CI}$ & $p^{b}$ & $\mathrm{aPR}$ & $95 \%$ CI & n & $\%$ & $95^{\circ} \% \mathrm{CI}$ & $p^{b}$ & $\mathrm{aPR}$ & $95^{\circ} \circ \mathrm{CI}$ \\
\hline TOTAL & 192 & 8.2 & 7.2-9.4 & & & & 760 & 31.9 & $30.0-33.8$ & & & \\
\hline \multicolumn{13}{|l|}{ Sex } \\
\hline Boys & 85 & 7.1 & $5.8-8.7$ & & 1 & & 391 & 32.3 & $29.7-35.0$ & & 1 & \\
\hline Girls & 107 & 9.4 & $7.8-11.2$ & & 1.32 & $1.01-1.74$ & 369 & 31.4 & $28.8-34.1$ & & 0.97 & $0.86-1.08$ \\
\hline Age (years) & & & & 0.273 & & & & & & $<0.00$ & & \\
\hline $0-3$ & 64 & 8.8 & $7.0-11.1$ & & 1 & & 134 & 24.5 & $21.1-28.3$ & & 1 & \\
\hline $4-7$ & 67 & 8.6 & $6.8-10.8$ & & 0.97 & $0.70-1.35$ & 295 & 37.3 & $34.0-40.7$ & & 1.49 & $1.25-1.77$ \\
\hline 8-11 & 61 & 7.3 & 5.8-9.3 & & 0.82 & $0.58-1.14$ & 331 & 38.7 & $35.5-42.0$ & & 1.55 & $1.31-1.84$ \\
\hline
\end{tabular}


Table 1B. Continued

\begin{tabular}{|c|c|c|c|c|c|c|c|c|c|c|c|c|}
\hline & \multicolumn{6}{|c|}{ Public transport (including stations) } & \multicolumn{6}{|c|}{ School \& nursery gates } \\
\hline & n & $\%$ & $95^{\circ} \% \mathrm{CI}$ & $p^{b}$ & $\mathrm{aPR}$ & $95 \%$ CI & n & $\%$ & $95^{\circ} \circ \mathrm{CI}$ & $p^{b}$ & aPR & $95^{\circ} \circ \mathrm{CI}$ \\
\hline $\begin{array}{l}\text { Education of } \\
\text { home main earner }\end{array}$ & & & & 0.267 & & & & & & $<0.001$ & & \\
\hline Primary & 34 & 10.0 & $7.3-13.7$ & & 1.28 & $0.88-1.88$ & 108 & 33.2 & $28.3-38.5$ & & 1.07 & $0.89-1.29$ \\
\hline Secondary & 77 & 8.1 & $6.5-10.0$ & & 1.05 & $0.77-1.42$ & 355 & 39.9 & $36.7-43.1$ & & 1.28 & $1.13-1.45$ \\
\hline University & 81 & 7.8 & 6.3-9.6 & & 1 & & 293 & 30.2 & $27.4-33.2$ & & 1 & \\
\hline $\begin{array}{l}\text { Social class of the } \\
\text { main earner }\end{array}$ & & & & 0.07 & & & & & & 0.04 & & \\
\hline I-II & 61 & 7.1 & $5.6-9.1$ & & & & 251 & 29.0 & $26.1-32.1$ & & & \\
\hline III-IV & 36 & 7.3 & $5.3-9.9$ & & & & 170 & 33.7 & $29.7-38.0$ & & & \\
\hline \multirow[t]{3}{*}{ V-VII } & 84 & 9.5 & 7.8-11.7 & & & & 303 & 33.7 & $30.7-36.8$ & & & \\
\hline & \multicolumn{6}{|c|}{ Leisure time } & \multicolumn{6}{|c|}{ Overall exposure $^{b}$} \\
\hline & $n$ & $\%$ & $95^{\circ} \% \mathrm{CI}$ & $p^{d}$ & aPR & $95 \% \mathrm{CI}$ & n & $\%$ & $95^{\circ} \% \mathrm{CI}$ & $p^{d}$ & $\operatorname{aPR}$ & $95^{\circ} \% \mathrm{CI}$ \\
\hline TOTAL & 1074 & 48.0 & $45.9-50.0$ & & & & 1637 & 71.8 & $\begin{array}{l}69.9- \\
73.6-\end{array}$ & & & \\
\hline \multicolumn{13}{|l|}{ Sex } \\
\hline Boys & 558 & 48.7 & $45.9-51.6$ & & 1 & & 832 & 71.5 & $68.9-74.1$ & & 1 & \\
\hline Girls & 516 & 47.1 & $44.2-50.1$ & & 0.97 & $0.89-1.06$ & 805 & 72.0 & $69.3-74.6$ & & 1.01 & $0.96-1.06$ \\
\hline Age (years) & & & & 0.09 & & & & & & 0.011 & & \\
\hline $0-3$ & 343 & 50.3 & $46.6-54.0$ & & 1 & & 481 & 68.8 & $65.3-72.1$ & & 1 & \\
\hline $4-7$ & 363 & 48.1 & $44.5-51.6$ & & 0.95 & $0.86-1.06$ & 542 & 71.3 & $68.0-74.4$ & & 1.04 & $0.97-1.11$ \\
\hline $8-11$ & 368 & 45.8 & $42.4-49.3$ & & 0.91 & $0.82-1.01$ & 614 & 74.7 & 71.6-77.6 & & 1.08 & $1.01-1.15$ \\
\hline $\begin{array}{l}\text { Education of } \\
\text { home main earner }\end{array}$ & & & & 0.371 & & & & & & $<0.001$ & & \\
\hline Primary & 162 & 48.1 & $42.8-53.4$ & & 1.04 & $0.92-1.19$ & 259 & 76.2 & $71.4-80.4$ & & 1.12 & $1.04-1.20$ \\
\hline Secondary & 456 & 49.5 & $46.3-52.7$ & & 1.07 & $0.98-1.18$ & 696 & 74.4 & $71.5-77.1$ & & 1.09 & $1.03-1.15$ \\
\hline University & 452 & 46.5 & $43.4-49.6$ & & 1 & & 677 & 68.0 & $65.0-70.8$ & & 1 & \\
\hline $\begin{array}{l}\text { Social class of the } \\
\text { main earner }\end{array}$ & & & & 0.95 & & & & & & 0.01 & & \\
\hline I-II & 388 & 48.3 & $44.8-51.7$ & & & & 574 & 69.7 & $66.5-72.8$ & & & \\
\hline III-IV & 226 & 46.8 & $42.4-51.3$ & & & & 338 & 69.7 & $65.5-73.6$ & & & \\
\hline V-VII & 410 & 48.4 & $45.1-51.8$ & & & & 651 & 75.3 & $72.3-78.0$ & & & \\
\hline
\end{tabular}

aPR: adjusted Prevalence Ratio, Cl: Confidence Interval

a Includes bars, cafes, restaurants or terraces, leisure centers, parks, family or friends' houses, or other places, $b$ Exposure in at least one of the private and public settings studied, c Social class according to the National Classification of Occupations (NCO-2011) proposed by the Spanish Society of Epidemiology6 (I-II: Directors, managers and university professionals; III-IV: Intermediate activities and own account workers; V-VII: Manual workers), d Mantel-Haenzel Test for linear trend

in Tables). An exposure gradient of SHS exposure at home was observed according to SES : the higher the educational level at home, the lower the exposure (38.8\% in families with primary school or lower, $28.7 \%$ with secondary school and $20.8 \%$ with university level, $p$ trend $<0.001$ ); conversely, the more deprived the social class, the higher the exposure $(21.7 \%$ class I-II, $23.4 \%$ class III-IV and $31.1 \%$ class V-VII, $\mathrm{p}$ trend $<0.001)$. SHS exposure in cars and overall SHS exposure also decreased as the educational attainment at home increased. The gradient observed according to education level remains in homes and cars, after adjusting by the other variables (Home: adjusted Prevalence Ratio, aPR=2.07, 95\%CI: 1.243.44 primary studies, aPR $=1.60,95 \% \mathrm{CI}: 1.04-2.44$ secondary studies; Car: aPR=1.89, 95\%CI: 1.58 - 
2.26 primary studies, aPR=1.39, 95\%CI: $1.19-1.63$ secondary studies).

\section{DISCUSSION}

In Spain, nearly 3 out of 4 children were exposed to SHS. Approximately $50 \%$ of the children were exposed during leisure time, more than $30 \%$ at the school gates and 26\% were exposed at home. Overall SHS exposure was higher in children whose parents had primary and secondary school education compared to children whose parents had university education. These differences were especially clear in the case of SHS exposure at home and in cars, for primary school education $(\mathrm{aPR}=2.07$ and 1.89 , respectively).

When the different settings were taken into account, SHS exposure affected more than $70 \%$ of the children. Therefore, as there is no level of SHS exposure that can be considered safe, it is important to include all these settings in public health studies. In a study carried out on adults in Spain in $2011^{7}$, we found a prevalence of overall SHS exposure (including home, work, transport, and leisure time) of $45.2 \%$, indicating that children, who are especially vulnerable, were even more exposed than adults.

One of the settings that has been most widely studied is the home. In this setting, the prevalence of exposure in our study was $26 \%$. Furthermore, according to a recent study ${ }^{8}$, the level of exposure in this setting might be very high, with nicotine concentration levels similar to those found in public places before the implementation of the tobacco control laws. Therefore, SHS exposure at home might have an important public health impact.

The inequalities observed with educational attainment were also found for social class. This finding is consistent with previous studies. A study carried out in Denmark showed that children were 11 times more likely to be exposed to SHS at home if the parents had a very low education level than if they were highly educated ${ }^{9}$. Another study carried out in Australia showed that the proportion of children who lived with a smoker declined between 2001 and 2010 in all social groups except the most disadvantaged households ${ }^{10}$. The results of another study carried out in Germany ${ }^{11}$ showed that 0-6 years old children with a low SES were more frequently exposed to SHS in the parental home (19.4\% for low SES, $4.7 \%$ for medium SES, and $1.7 \%$ for high SES).
In our study, SHS exposure in cars was $4.6 \%$, and a trend was also observed according to educational attainment at home. This prevalence is slightly higher than that registered in an observational study in Barcelona ${ }^{12}$ in which $2.2 \%$ of passengers younger than 14 years were exposed to SHS in vehicles. The inequalities found are also consistent with a recent study showing that SHS exposure of children traveling in cars that were registered in the most disadvantaged areas of Montreal were more likely to be exposed than children traveling in cars registered in the most advantaged areas ${ }^{13}$.

One of the potential limitations of this study is the use of a non-validated questionnaire. However, the design of the questionnaire was based on a previous questionnaire $^{7,14,15}$, used to assess SHS in adults and was adapted ad-hoc to our population. In addition, a pilot test was conducted on 30 participants to minimize its potential limitations. The use of a questionnaire could also represent information bias since the respondents may not know if the children had been exposed when they were not with them. A desirability bias, with some parents underreporting the real SHS exposure, might also be possible. Finally, we do not have information about potential SHS exposure from external smokers in multi-unit housing, which may underestimate SHS exposure at home.

A strength of the study is that it was conducted in a representative national sample of children younger than 12 years in Spain. This is also the first study to show data on SHS exposure of children in multiple settings at the national level, as most previous studies have focused on homes or other selected settings. Finally, our study included two different, and very widely used, socioeconomic indicators to assess inequalities-educational level and social class-both of which showed the same pattern.

\section{CONCLUSIONS}

This study shows that, despite the laws, a large proportion of children might still be exposed to SHS. Furthermore, there are clear social inequalities. Therefore, there is a need for evidence-based interventions with an equity perspective to reduce SHS exposure of children.

\section{REFERENCES}

1. Lopez MJ, Continente X. Secondhand smoke exposure in 
children: It is time to move forward. Rev Port Pneumol. 2016;22(4):187-188. doi:10.1016/j.rppnen.2016.05.002

2. Orton S, Jones LL, Cooper S, Lewis S. Predictors of Children's Secondhand Smoke Exposure at Home: A Systematic Review and Narrative Synthesis of the Evidence. PLoS ONE. 2014;9(11): e112690. doi:10.1371/journal.pone.0112690

3. Law $28 / 2005$. Ley $28 / 2005$, de 26 de diciembre, de medidas sanitarias frente al tabaquismo y reguladora de la venta, el suministro, el consumo y la publicidad de los productos del tabaco. https://www.boe.es/boe/ $\operatorname{dias} / 2005 / 12 / 27 / p d f$ s/A42241-42250.pdf. Published December 28, 2005. Accessed September 28, 2016.

4. Law 42/2010. Ley 42/2010, de 30 de diciembre, por la que se modifica la Ley $28 / 2005$, de 26 de diciembre, de medidas sanitarias frente al tabaquismo y reguladora de la venta, el suministro, el consumo y la publicidad de los productos del tabaco. https://www.boe.es/boe/dias/2010/12/31/ pdfs/BOE-A-2010-20138.pdf. Published December 30, 2010. Accessed September 28, 2016.

5. Spanish Ministry of Health, Social Services and Equality. Spanish National Health survey 2011/12: Health determinants (absoulte values and means). http://www. msc.es/estadEstudios/estadisticas/encuestaNacional/ encue sta $\mathrm{Nac} 2011 / 2 \mathrm{Determinantes} \mathrm{Salud}$ DistribucionPorcentual.pdf. Published 2013. Accessed October 11, 2016.

6. Domingo-Salvany A, Bacigalupe A, Carrasco JM, Espelt A, Ferrando J, Borrell C, et al. [Proposals for social class classification based on the Spanish National Classification of Occupations 2011 using neo-Weberian and neoMarxist approaches]. Gac Sanit. 2013;27(3):263-272. doi:10.1016/j.gaceta.2012.12.009.

7. Fernández E, Fu M, Pérez-Ríos M, Schiaffino A, Sureda X, López MJ. Changes in secondhand smoke exposure after smoke-free legislation (Spain, 2006-2011). Nicotine Tob Res. 2017;19(11):1390-1394. doi:10.1093/ntr/ntx040

8. Arechavala T, Continente X, Pérez-Ríos M, Schiaffino A, FernandezE, Cortés-FranciscoN, etal. Second-hand smoke exposure in homes with children: assessment of airborne nicotine in the living room and children's bedroom. Tob Control. 2017:tobaccocontrol-2017-053751. doi:10.1136/tobaccocontrol-2017-053751

9. Pisinger C, Hammer-Helmich L, Andreasen AH, Jørgensen T, Glümer C. Social disparities in children's exposure to second hand smoke at home: a repeated cross-sectional survey. Environ Health. 2012;11(1):1. doi:10.1186/1476-069x-11-65

10.Gartner GE, Hall WD. Is the socioeconomic gap in childhood exposure to secondhand smoke widening or narrowing? Tob Control. 2013;22(5):344-348. doi:10.1136/tobaccocontrol-2011-050297

11. Kuntz B, Lampert T. Social disparities in parental smoking and young children's exposure to secondhand smoke at home: a time-trend analysis of repeated cross-sectional data from the German KiGGS study between 2003-2006 and 2009-2012. BMC Public Health. 2016;16(485). doi:10.1186/s12889-016-3175-x

12. Curto A, Martínez-Sánchez JM, Fernández E. Tobacco consumption and secondhand smoke exposure in vehicles: a cross-sectional study. BMJ Open. 2011;1(2):e000418. doi:10.1136/bmjopen-2011-000418

13. Montreuil A, Hanusaik N, Cantinotti M, Leclerc BS, Kestens Y, Tremblay M, et al. Social disparities in children's exposure to secondhand smoke in privately owned vehicles. Tob Control. 2016;26(6):663-668. doi:10.1136/tobaccocontrol-2016-053347

14. Perez-Rios M, Fernandez E, Schiaffino A, Nebot M, López MJ. Changes in the Prevalence of Tobacco Consumption and the Profile of Spanish Smokers after a Comprehensive Smoke-Free Policy. PLoS ONE. 2015;10(6). doi:10.1371/journal.pone.0128305

15. López MJ, Pérez-Ríos M, Schiaffino A, Fernández E. Mortality Attributable to Secondhand Smoke Exposure in Spain (2011). Nicotine Tob Res. 2016;18(5):1307-1310. doi:10.1093/ntr/ntv130
CONFLICTS OF INTEREST

Authors have completed and submitted the ICMJE Form for Disclosure of Potential Conflicts of Interest and none was reported.

FUNDING

This study was funded by the Instituto Carlos III (PN I+D+I 2013-2016) and co-funded by the European Regional Development Fund (FEDER) under grant PI13/02734. The study was also partially funded by the Ministry of Universities and Research of Catalonia (AGAUR) under grant 2014 SGR 1373.

PROVENANCE AND PEER REVIEW Not commissioned; externally peer reviewed 